\title{
Recent researches on prebiotics for gut health in Thailand
}

\section{Santad Wichienchot ${ }^{1^{*}}$, Wirote Youravong ${ }^{2}$, Suwattana Prueksasri ${ }^{3}$ and BudsarapornNgampanya ${ }^{3}$}

${ }^{1}$ Interdisciplinary Graduate School of Nutraceutical and Functional Food, Prince of Songkla University, Hat Yai, Songkhla 90112, Thailand; ${ }^{2}$ Department of Food Technology, Faculty of Agro-Industry, Prince of Songkla University, Hat Yai, Songkhla 90112, Thailand; ${ }^{3}$ Department of Biotechnology, Faculty of Engineering and Industrial Technology, Silpakorn University, Nakorn Pathom 73000, Thailand

*Corresponding author: Santad Wichienchot, ${ }^{1}$ Interdisciplinary Graduate School of Nutraceutical and Functional Food, Prince of Songkla University, Hat Yai, Songkhla 90112, Thailand

Submission Date: July 25, 2015, Acceptance date: November 24, 2015: Publication date: November 29, 2015

\begin{abstract}
Background: In the food industries, several oligosaccharides have received increasing attention as key components for functional foods and nutraceutical products. Prebiotics are non-digestible oligosaccharides which have been shown to have properties that can modulate gastrointestinal problems and improve gut health and well-being. Recent researches much pay attention to find alternative sources, improve specific properties and proof on health benefits of these prebiotics.
\end{abstract}

Methods: This is the summary of research works have been done by our research group on prebiotics and gut health in Thailand. These works aimed to study sources of prebiotics from fruits and vegetables in Thailand, production by enzymatic synthesis of prebiotics, purification by microbial fermentation and membrane technology and applications of the prebiotics in nutraceuticals and functional foods.

Results: Among the 30 parts of 14 plants, six appear to have the highest potential for commercialization based on extract yield and the amount and type of indigestible oligosaccharides. These include dragon fruit, palm flesh, palm embryo, jackfruit flesh, jackfruit seed, and okra pod. At least three of them, dragon fruit, jackfruit flesh and seed, were confirmed on their prebiotic property by selectively in vitro colonic microflora fermentation in an artificial colon system. Among 52 LAB isolates for production of GOS, BFP32 showed highest intracellular $\beta$-galactosidase activity and GOS yield. It was identified as Lactobacillus pentosus var. plantarum by $16 \mathrm{~S}$ rDNA sequencing. Composition of GOS consisted of oligosaccharides with having DP of 3,4 and 5. A mixture of GOS was purified successful by sequential bacterial 
and yeast fermentation whereas nanofiltration could be used for partial purification. Prebiotic index (PI) of the GOS produced was1.19 in batch culture. A crude extract from tubers of Jerusalem artichoke (Helianthus tuberosus L.) had transfructosylating activity for biosynthesis of FOS from sucrose. Optimal conditions for production of FOS were 0.26 U FTase, incubated with $0.46 \mathrm{M}$ sucrose as substrate at $\mathrm{pH} 5.4$ and $35^{\circ} \mathrm{C}$ for $144 \mathrm{~h}$. A maximum yield of scFOS (DP<5) was obtained $(54.46 \%)$. The scFOS showed prebiotic property with PI of 1.29 in batch culture. Four formulas of canned tuna in spring water and tuna in mayonnaise and pouched tuna in salad cream and tuna in thousand island cream with added inulin were developed for commercial production. An addition of $5 \%$ inulin for tuna in spring water and $7 \%$ inulin for tuna in mayonnaise, tuna in thousand island and tuna in salad cream are recommended. The highest prebiotic index (PI) scores of tuna in spring water and tuna in salad cream added $5 \%$ inulin were 1.82 and 0.93 , respectively in three-stage continuous culture. In clinical study of tuna products, it was found that $5 \%$ inulin addition helps on improve of bowel regularity. By-product from rubber wood sawdust could be used as alternative source of XOS. Among eight edible commercial mushrooms, Schizophyllum communehad highest total $\beta$-glucan content (59.87\% dry basis).

Conclusions: Research on prebiotics in Thailand had two mainly approaches including by extraction from natural occurring in fruits and vegetables and by enzymatic approach using hydrolysis and transferase activities from agricultural by-products and low cost raw materials. Prebiotic researches are covered in vitro, in vivo in rat and being investigated in clinical study related to gut health functional and immunity.

Keywords: Prebiotic, Functional carbohydrate, Gut health, Fecal fermentation, Clinical study

\section{BACKGROUND}

Prebiotic is emerging functional food ingredient. It is classified as soluble dietary fiber that mostly composes of oligosaccharides which can promote the growth of beneficial microorganisms or probiotics. Health claim for consumption of prebiotic is improve on gut health function and nutrient claim is as source of dietary fiber [1]. Prebiotic is one of the prevention alternatives. Prebiotics are nonviable food components which escape digestion in the upper gut, are fermented by probiotics or beneficial bacteria. Prebiotics are distinguished from other dietary fibers because of it has special property on selective fermentation by bifidobacteria/ lactobacilli within the gut microflora [2]. In addition, prebiotic has been linked to improved colon health by promoting bifidobacteria and/or lactobacilli populations, and increased absorption of calcium and minerals [3]. Currently, most prebiotics developed are the non-digestible oligosaccharides i.e. fructo-oligosaccharides (FOS), galactooligosaccharides (GOS), xylooligosaccharides (XOS), isomaltooligosaccharides (IMO), soybean oligosaccharides (SOS), lactulose, lactosucrose except for polysaccharide-inulin [4]. Probiotics are beneficial bacteria particular bifidobacteria and lactobacilli. Probiotics have been demonstrated to impact on the immune function and such approaches may be useful in stimulation of the aging, dysregulated immune system bringing about reduced inflammatory responses, and balancing gut microbiota [5]. 
Prebiotic and probiotic researches in Thailand have been studied on several aspects such as alternative sources of prebiotic from fruits and vegetables in Thailand, and functionalities and properties of prebiotics to gut microbiota and gut health. The researches were focused on study the possibility of agricultural raw materials in Thailand to replace sources of commercial prebiotics. In the food industries, several oligosaccharides have received increasing attention as key components for functional foods and nutraceuticals products. Prebiotics are non-digestible oligosaccharides which have been shown to have properties that can modulate gastrointestinal problems and improve gut health and well-being. Recent researches much pay attention to find alternative sources, improve specific properties and proof on health benefits of these prebiotics.

\section{MATERAILS AND METHODS}

Wichienchot and colleagues [6] were studied on several plants as source of prebiotic in Thailand and studied on optimal conditions for extraction of oligosaccharides from plants. Thirteen types of fruits and vegetables commonly grown and consumed in southern Thailand were selected based on their physicochemical characteristics, which suggested the presence of prebiotics or soluble dietary fiber, abundance, low cost, and the amount of waste they generated that could be utilized. Table 1 lists the plants and their parts used in the studies. Samples were analyzed for moisture content, extract yield, and indigestible polysaccharide concentrations were investigated.

Table 1 Plants and their various parts used in the analysis for prebiotics.

\begin{tabular}{|c|c|}
\hline Plant & Part used in the studies \\
\hline $\begin{array}{l}\text { Banana (Musa sapientum Linn.; Thai name: } \\
\text { Kluay Naam Wah), a. mature green, b. ripe } \\
\text { Okra (Hibiscus esculentus Linn.; Thai name: } \\
\text { Krajiab Kheaw), mature green }\end{array}$ & $\begin{array}{l}\text { a. Skin } \\
\text { b. Flesh } \\
\text { a. Pod }\end{array}$ \\
\hline $\begin{array}{l}\text { Jackfruit (Artocarpus heterophyllus Lam.; Thai } \\
\text { name: Ka Nhoon), ripe }\end{array}$ & $\begin{array}{l}\text { a. Skin (inner rind, i.e. } \\
\text { excluding the outer skin) } \\
\text { b. Flesh } \\
\text { c. Seed }\end{array}$ \\
\hline $\begin{array}{l}\text { Germinated brown rice (Oryza sativa Linn.; } \\
\text { Thai name: Kao Ngog) }\end{array}$ & a. Germinated grain \\
\hline $\begin{array}{l}\text { Rambutan (Nephelium lappaceum Linn.; } \\
\text { Thai name: Ngoh), ripe }\end{array}$ & $\begin{array}{l}\text { a. Peel } \\
\text { b. Flesh } \\
\text { c. Seed }\end{array}$ \\
\hline $\begin{array}{l}\text { Durian (Durio zibethinus Linn.; Thai name: } \\
\text { Turian), ripe }\end{array}$ & a. Shell \\
\hline Jampadah (Artocarpus integer Merr.), ripe & $\begin{array}{l}\text { a. Skin } \\
\text { b. Flesh } \\
\text { c. Seed }\end{array}$ \\
\hline $\begin{array}{l}\text { Huasa potato (Coleus parvifolius Benth; Thai } \\
\text { name: Man Kee Nhoo), mature }\end{array}$ & a. Tuber \\
\hline $\begin{array}{l}\text { Tamarind (Tamarindus indica Linn.; Thai name: } \\
\text { Ma Kham), ripe }\end{array}$ & $\begin{array}{l}\text { a. Flesh } \\
\text { b. Seed coat }\end{array}$ \\
\hline
\end{tabular}




\begin{tabular}{|c|c|c|}
\hline & Plant & Part used in the studies \\
\hline \multirow{4}{*}{0} & & c. Seed cotyledon \\
\hline & Coconut (Cocos nucifera Linn.; Thai name: Ma & a. Flesh \\
\hline & Prao), young fruit & \\
\hline & Mango (Mangifera indica Linn.; Thai name: Ma & a. Skin \\
\hline 1 & Muang), mature green & b. Flesh \\
\hline & & Seed \\
\hline 2 & $\begin{array}{l}\text { Fan palm fruit (Borassus flabellifer Linn.; Thai } \\
\text { name: Luke Taan) }\end{array}$ & $\begin{array}{l}\text { a. Pericarp of ripe fruit } \\
\text { b. Flesh from young fruit } \\
\text { c. Embryo }\end{array}$ \\
\hline 3 & $\begin{array}{l}\text { Dioscorea tuber (Dioscorea membranacea Pierre; } \\
\text { Thai name: Hua Khao Yen) }\end{array}$ & b. Tuber \\
\hline
\end{tabular}

Galactooligosaccharide (GOS) was produced according to the study of Hemmaratchirakul and co-workers [7]. The $\beta$-galactosidase was partially purified from Lactobacillus pentosus var. plantarum BFP32. This strain was isolated from fermented pork sausage that could produce $\beta$ galactosidase. The enzymatic reaction was carried out by mixing $\beta$-galactosidase with lactose or milk in batch and UF membrane reactor. Effect of reaction $\mathrm{pH}$ and temperatures for production of GOS were investigated. The method for purification of GOS was done using diafiltration technique in nanofiltration membrane. Optimal conditions for production and purification of GOS have been investigated. Chemical composition of GOS was determined by HPLC. Prebiotic property of the GOS was studied in batch culture system. Prebiotic index (PI) was calculated according to the changes of bifidobacteria, lactobacilli, bacteroides, clostridia and eubacteria (total bacteria) by fluorescence in situ hybridization (FISH) technique.

Fructooligosaccharide (FOS) was produced by study of Prakobpran et al. [8]. Fructosyltranferase (FTase) was extracted from tuber of Jerusalem artichoke (Helianthus tuberosus L.). The enzyme was further purified by two chromatographic steps (anion exchange and affinity chromatography). The FTase was studied on kinetics for FOS synthesis using sucrose as substrate. Optimal conditions for production of FOS were investigated. Chemical compositions of FOS was analyzed by HPLC. Purification of FOS was successful by yeast fermentation to remove residual sugars. Prebiotic property of FOS was studied in batch culture by fecal fermentation. Prebiotic index (PI) was calculated according to the population changes of 5 bacterial genus by fluorescence in situ hybridization (FISH) technique.

Four formulas of tuna products added inulin were developed together with Tropical Canning (Thailand) Public Company Limited, Songkhla, Thailand. These products were canned tuna in spring water and tuna in mayonnaise and pouched tuna in salad cream and tuna in thousand island cream. Addition of inulin at 3, 5, 7 and 10\%, w/w was studied. The effects of the addition of a prebiotic (inulin, Orafti ${ }^{\circledR}$-HP) on the physical properties and sensory properties of these products were studied. The canned tuna in spring water and pouched tuna in salad cream were fermented in in vitro fecal fermentation with three-stage continuous system [9]. The efficacy of tuna products added 5\% inulin were evaluated on their benefits to gut health by 30 volunteers consumption for 2 weeks. Feces was taken to enumerate bacterial by FISH technique and questionnaire was asked for type and odor of faces, mass of faces and frequency of defecation. 
Xylooligosaccharides (XOS) was produced from rubber wood sawdust. Rubber wood sawdust was sieved through sieve No. $20 \mathrm{MESH}$ to obtain small size then it was soaked in water. The extraction of xylan from rubber wood sawdust had two methods; alkaline extraction, and acid extraction. Xylans were further hydrolyzed by xylanase to obtain XOS. Optimal conditions for production of XOS were investigated. The chemical compositions of XOS were determined by HPLC and molecular weight distribution was analyzed by HPSEC [10].

$\beta$-glucans from eight edible mushrooms (Schizophylum commune Fr, Auricularia auricula Judae, Pleurotus osttreatus, Pleurotus sajor-caju, Flammulina velutipes, Lentinus edodes, Volvariella vovacea and Boletus griseipurpureus) were investigated. Dried mushroom powder was pre-treated with cellulase. The pre-treated mushroom powder was further extracted in autoclave at temperature of $130{ }^{\circ} \mathrm{C}$ for 45 and 90 minutes to obtain $\beta$-glucan. Determination of $\beta$ glucan content in extractable solid of mushroom samples was done by a mushroom $\beta$-glucan kit. Cost of mushroom per $\beta$-glucan content, yield and $\beta$-glucan content of eight mushrooms were compared [11].

\section{RESULTS}

Among the 30 parts of 14 plants, six appear to have the highest potential for commercialization based on extract yield and the amount and type of indigestible oligo-polysaccharides. These include dragon fruit, palm flesh, palm embryo, jackfruit flesh, jackfruit seed, and okra pod. At least three of them, dragon fruit, jackfruit flesh and seed, were confirmed on their prebiotic property by selectively in vitro colonic microflora fermentation in an artificial colon system.

Table 2 Moisture content, extract yield, and indigestible oligo-polysaccharide concentrations in ten plant samples

\begin{tabular}{lllllll}
\hline Plant & Part & $\begin{array}{l}\text { Moisture } \\
\text { content } \\
(\% \text { wet } \\
\text { weight } \pm \text { SD) }\end{array}$ & Solvent & $\begin{array}{l}\text { Extract yield } \\
(\% \text { dry } \\
\text { weight } \pm \text { SD })\end{array}$ & $\begin{array}{l}\text { Indigestible } \\
\text { polysaccharides, } \\
\text { acid/enzyme } \\
\text { digestion (mg/g } \\
\text { dry extract } \pm \text { SD) })\end{array}$ & $\begin{array}{l}\text { Indigestible } \\
\text { polysaccha-rides, } \\
\mathrm{H}_{2} \mathrm{SO}_{4} \text { digestion } \\
\text { (oligosaccharides) } \\
(\mathrm{mg} / \mathrm{g} \text { dry extract) }\end{array}$ \\
\hline Palm fruit & Pericarp & $85.53 \pm 0.10$ & EtOH 95\% & $51.69 \pm 0.40$ & $705.80 \pm 3.83$ & 14.13 \\
Jackfruit & Skin & $88.65 \pm 0.03$ & EtOH 95\% & $71.54 \pm 0.01$ & $689.08 \pm 15.21$ & 0.00 \\
Jackfruit & Flesh & $81.76 \pm 0.01$ & EtOH 95\% & $59.43 \pm 0.07$ & $605.76 \pm 16.55$ & 98.05 \\
Rambutan & Flesh & $82.81 \pm 0.07$ & EtOH 50\% & $55.73 \pm 2.65$ & $566.83 \pm 8.42$ & 9.43 \\
Jampadah & Flesh & $69.83 \pm 0.06$ & EtOH 95\% & $34.11 \pm 0.12$ & $542.56 \pm 13.82$ & 2.40 \\
Young & Flesh & $86.45 \pm 0.06$ & CW & $22.66 \pm 5.59$ & $513.87 \pm 4.29$ & 0.00 \\
coconut & Pod & $89.99 \pm 0.03$ & EtOH 50\% & $12.39 \pm 0.01$ & $460.73 \pm 17.05$ & 49.15 \\
Okra & Embryo & $77.66 \pm 0.20$ & EtOH 50\% & $26.54 \pm 0.96$ & $409.85 \pm 2.88$ & 33.69 \\
Palm fruit & Seed & $71.50 \pm 0.20$ & EtOH 50\% & $16.00 \pm 0.08$ & $403.44 \pm 5.63$ & 29.35 \\
Jackfruit & Flesh & $91.99 \pm 0.04$ & EtOH 95\% & $44.94 \pm 0.26$ & $334.87 \pm 19.45$ & 47.20 \\
Palm fruit & & & & & & \\
\hline
\end{tabular}

$\mathrm{SD}=$ standard deviation; $\mathrm{EtOH}=$ ethanol, $\mathrm{CW}=$ water at ambient temperature. ${ }^{\text {a }} \mathrm{SD}$ was calculated from averaged SDs of total sugars and reducing sugars. ${ }^{b}$ Due to the calculation method used it was not practical to calculate SD. 
Among 52 lactic acid bacteria (LAB) isolates for production of GOS, BFP32 showed highest intracellular $\beta$-galactosidase activity and GOS yield. It was identified as Lactobacillus pentosus var. plantarum by $16 \mathrm{~S}$ rDNA sequencing. The optimal $\mathrm{pH}$ and temperature for synthesis of GOS were 7 and $50^{\circ} \mathrm{C}$, respectively (Figure 1). Composition of GOS consisted of oligosaccharides with having DP of 3,4 and 5. A mixture of GOS was purified successful by sequential bacterial and yeast fermentation whereas nano-filtration could be used for partial purification.
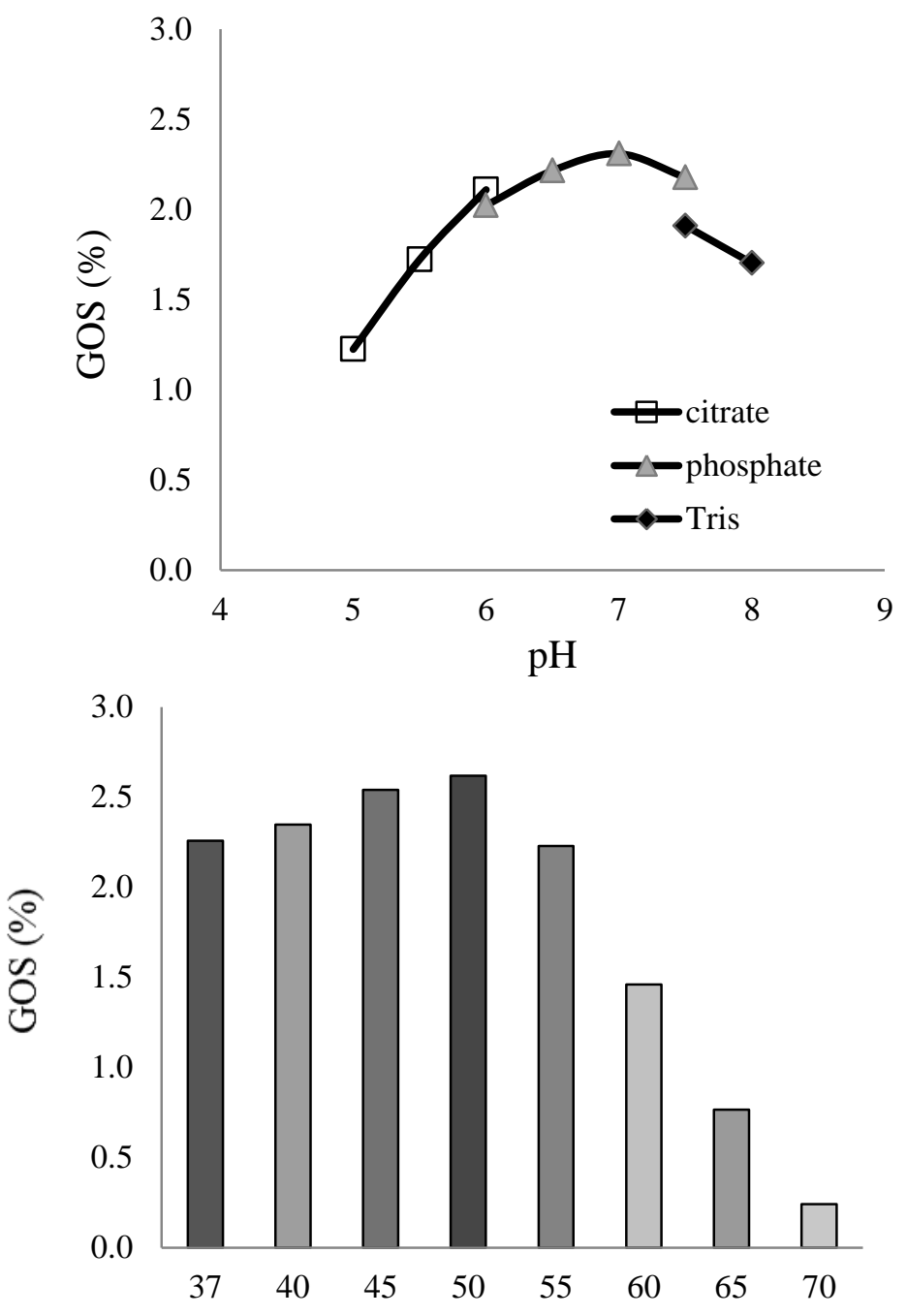

Figure 1. Production of galactooligosaccharide using $\beta$-galactosidase $(100 \mathrm{U} / \mathrm{ml})$ at $50{ }^{\circ} \mathrm{C}$ and pH 7.0 with $60 \%$ lactose as substrate; $(\mathbf{\square}) \mathrm{GOS} ;(\boldsymbol{\Delta})$ lactose; $(\boldsymbol{X})$ glucose; ( $)$ galactose.

Fermentation of GOS in fecal batch culture for evaluation of prebiotic property was performed. The results showed that GOS produced in the study and commercial GOS could increase lactobacillus and bifidobacteria significantly $(\mathrm{P}<0.05)$ (Figure 2). Prebiotic properties can be calculated from prebiotic index using numbers of cell counts by fluorescent in situ hybridization (FISH) technique. The population changes in numbers of lactobacilli, bifidobacteria, clostridia, bacteroides and eubacteria were calculated. The result showed positive 
prebiotic effects both GOS produced in the study and commercial GOS. GOS produced in the study has prebiotic index of1.19, and commercial GOS has prebiotic index of 1.68.Conversely, mixed sugars showed negative prebiotic effect $(\mathrm{PI}=-0.01)$ due to mixed sugars composed sugars that it was metabolized by mostly harmful fecal bacteria.

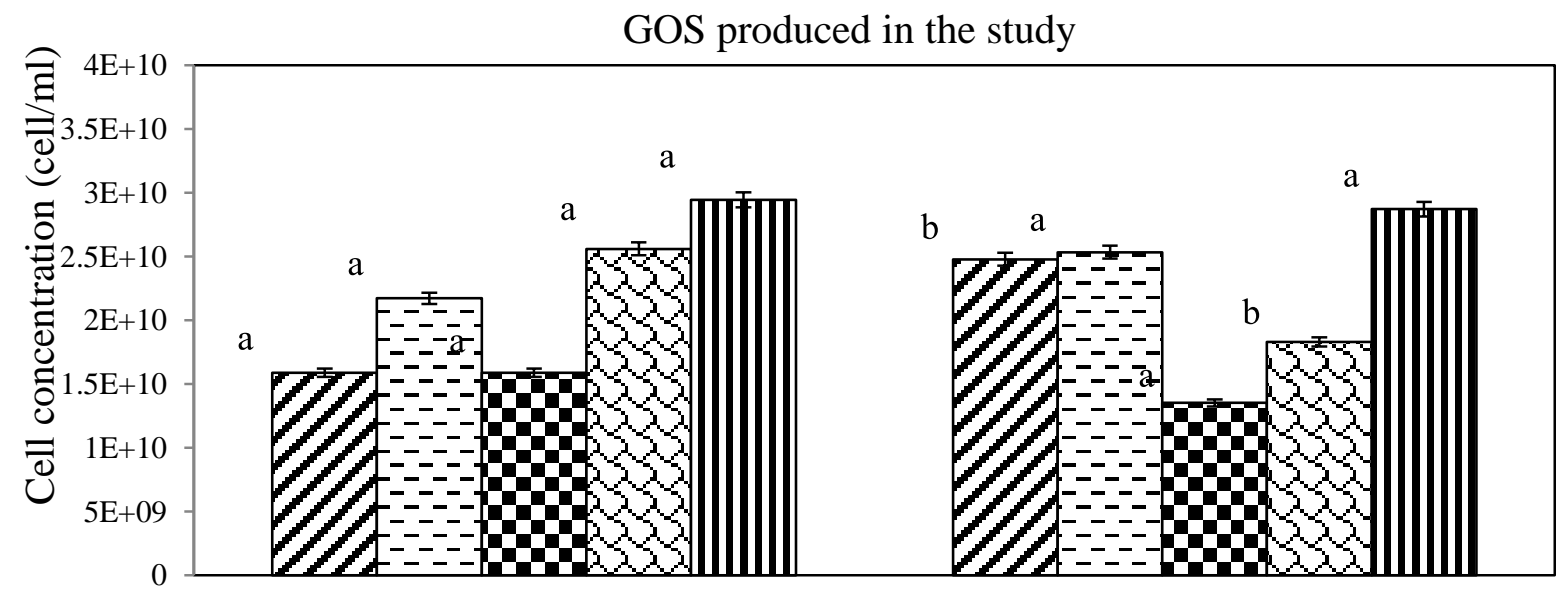

Mixed sugars

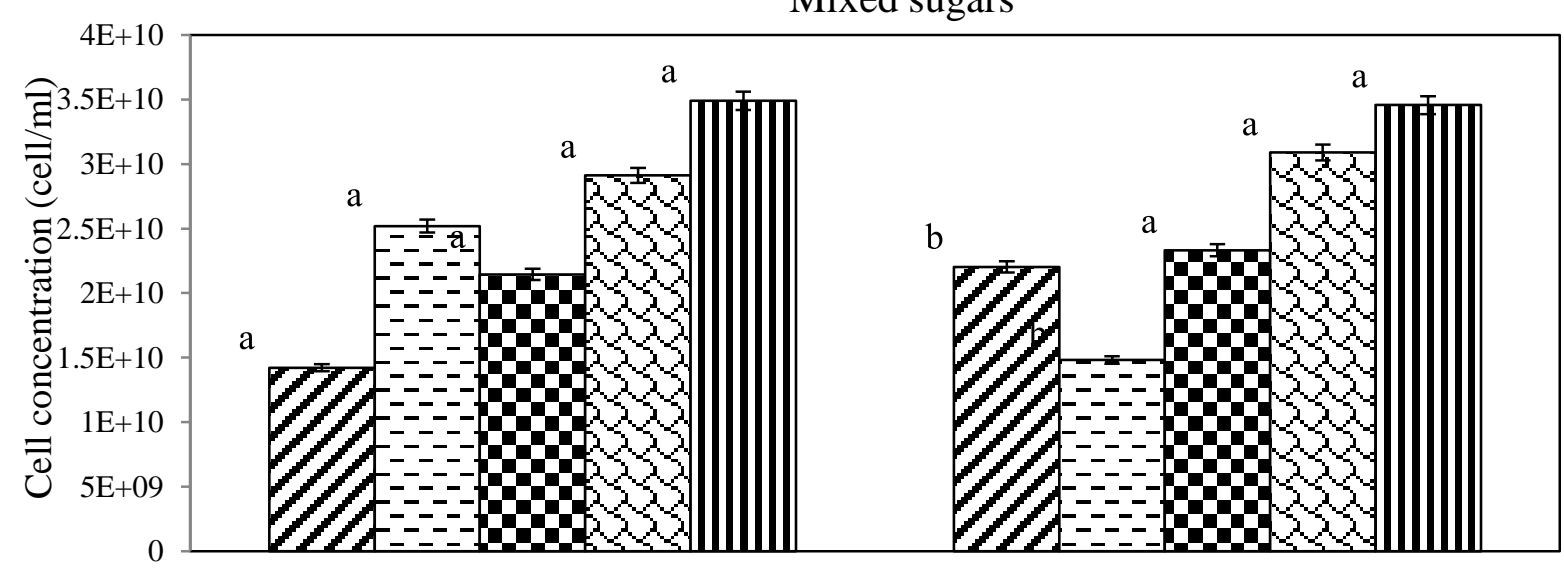

Commercial GOS

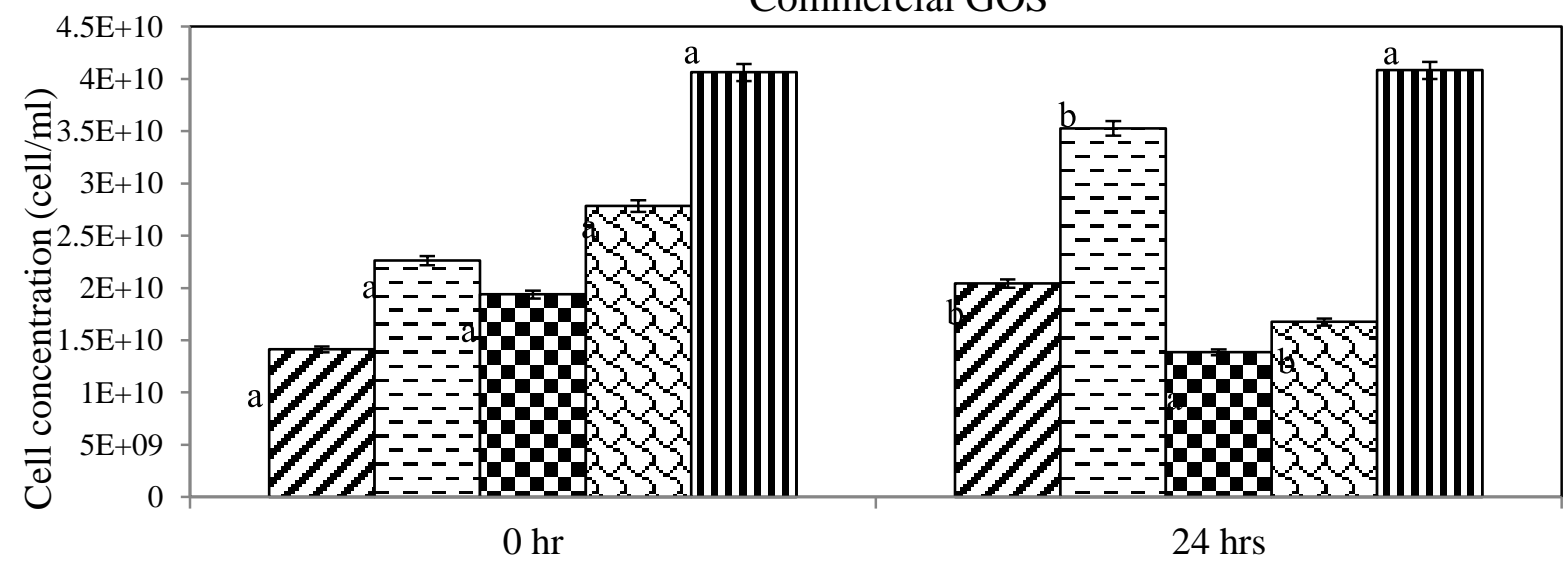

Figure 2. Cell concentrations in batch culture of GOS produced on the study, mixed sugars, and commercial GOS as carbon source at 0 and 24 hours; ( $(\boldsymbol{\square})$ Lactobacillus, (E)

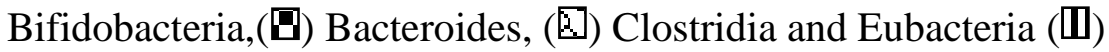

Different letters is statistically significant $(\mathrm{p}<0.05)$ 
A crude extract from tubers of Jerusalem artichoke (Helianthus tuberosus L.) had transfructosylating activity for biosynthesis of FOS from sucrose. Optimal conditions for production of FOS were $0.26 \mathrm{U}$ FTase, incubated with $0.46 \mathrm{M}$ sucrose as substrate at $\mathrm{pH} 5.4$ and $35^{\circ} \mathrm{C}$ for $144 \mathrm{~h}$. A maximum yield of scFOS (DP $\leq 5$ ) was obtained (54.46\%) (Figure 3).

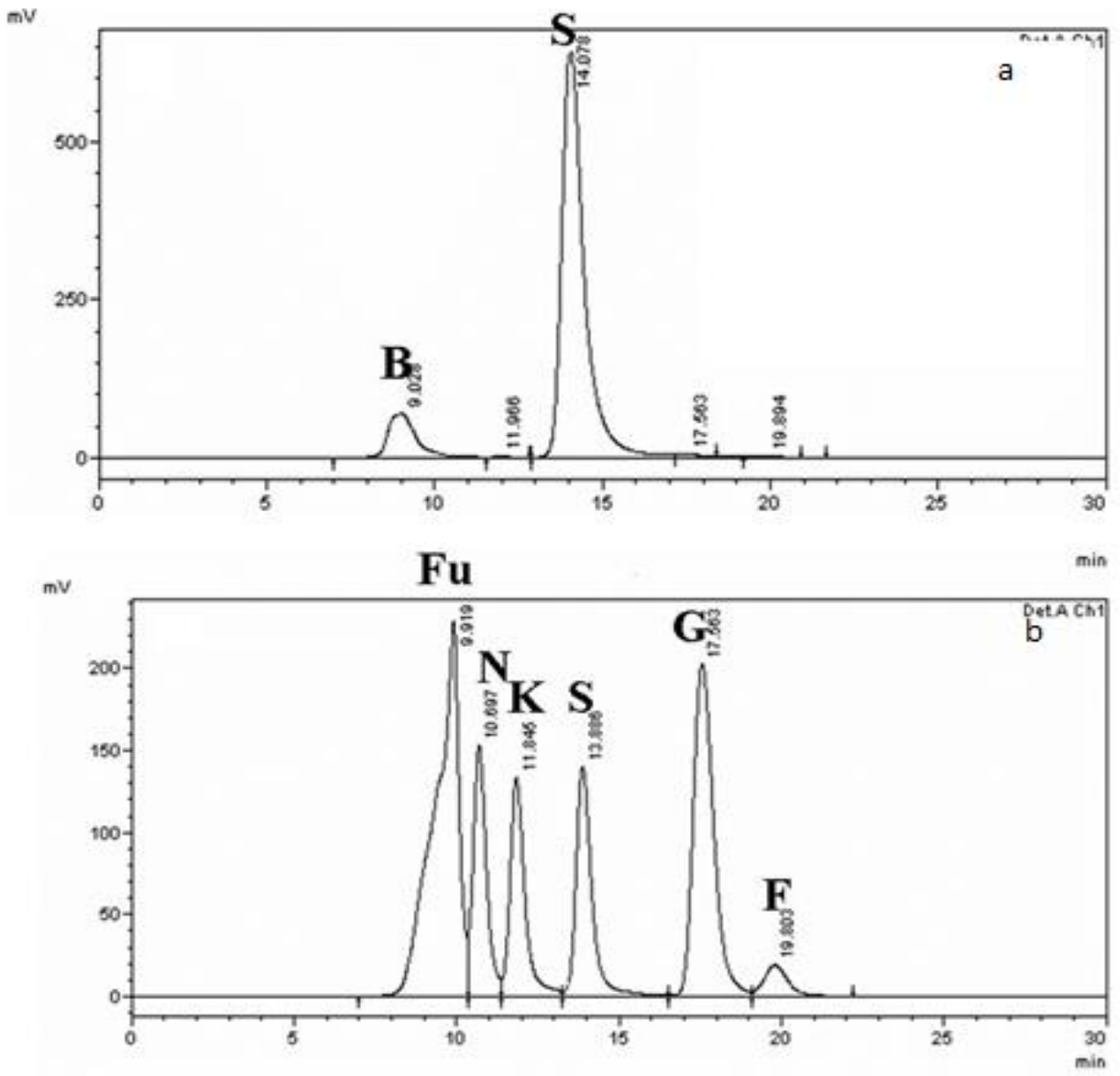

B: 0.1 M K phosphate buffer; S: Sucrose, F: Fructose; G: Glucose; S: Sucrose; K: 1-kestose $\left(\mathrm{GF}_{2}\right) ; \mathrm{N}$ : nystose $\left(\mathrm{GF}_{3}\right) ; \mathrm{Fu}: 1-\beta$-fructofuranosylnystose $\left(\mathrm{GF}_{4}\right)$

Figure 3. Production of FOS by enzymatic synthesis of 0.26 U FTase from 105-120 days old tubers of tropical Jerusalem artichoke and $0.46 \mathrm{M}$ sucrose as substrate, $\mathrm{pH} 5.4$ at $35^{\circ} \mathrm{C}$ for 0 (a) and $144 \mathrm{~h}(\mathrm{~b})$.

Fermentation of FOS in fecal batch culture system for evaluation of prebiotic property was tested. The result showed that FOS produced in the study and commercial FOS were significantly $(\mathrm{P}<0.05)$ increased numbers of lactobacilli, bifidobacteria and decreased number of clostridia groups (Figure 4). Meanwhile mixed sugar was significantly $(\mathrm{p}<0.05)$ increased bifidobacteria, clostridia but decrease lactobacilli.

Prebiotic properties were evaluated from prebiotic index. The microbial group that counted as lactobacilli, bifidobacteria, clostridia, bacteroides and eubacteria. The result showed positive value both FOS produced in the study and commercial FOS. FOS produced in the study and commercial FOS had prebiotic index of 1.29 and 1.14, respective. However, mixed sugars showed negative prebiotic effect with PI of -1.9. 


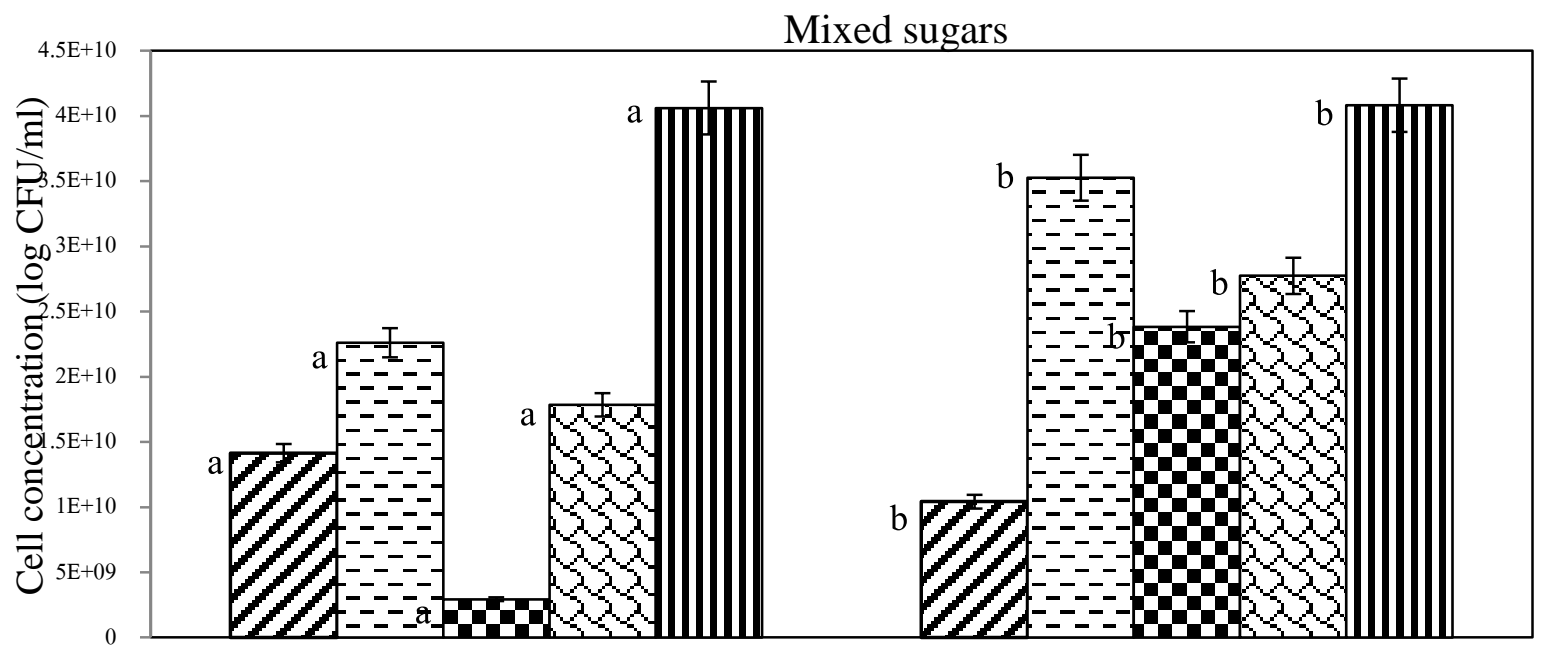

FOS produced in the study
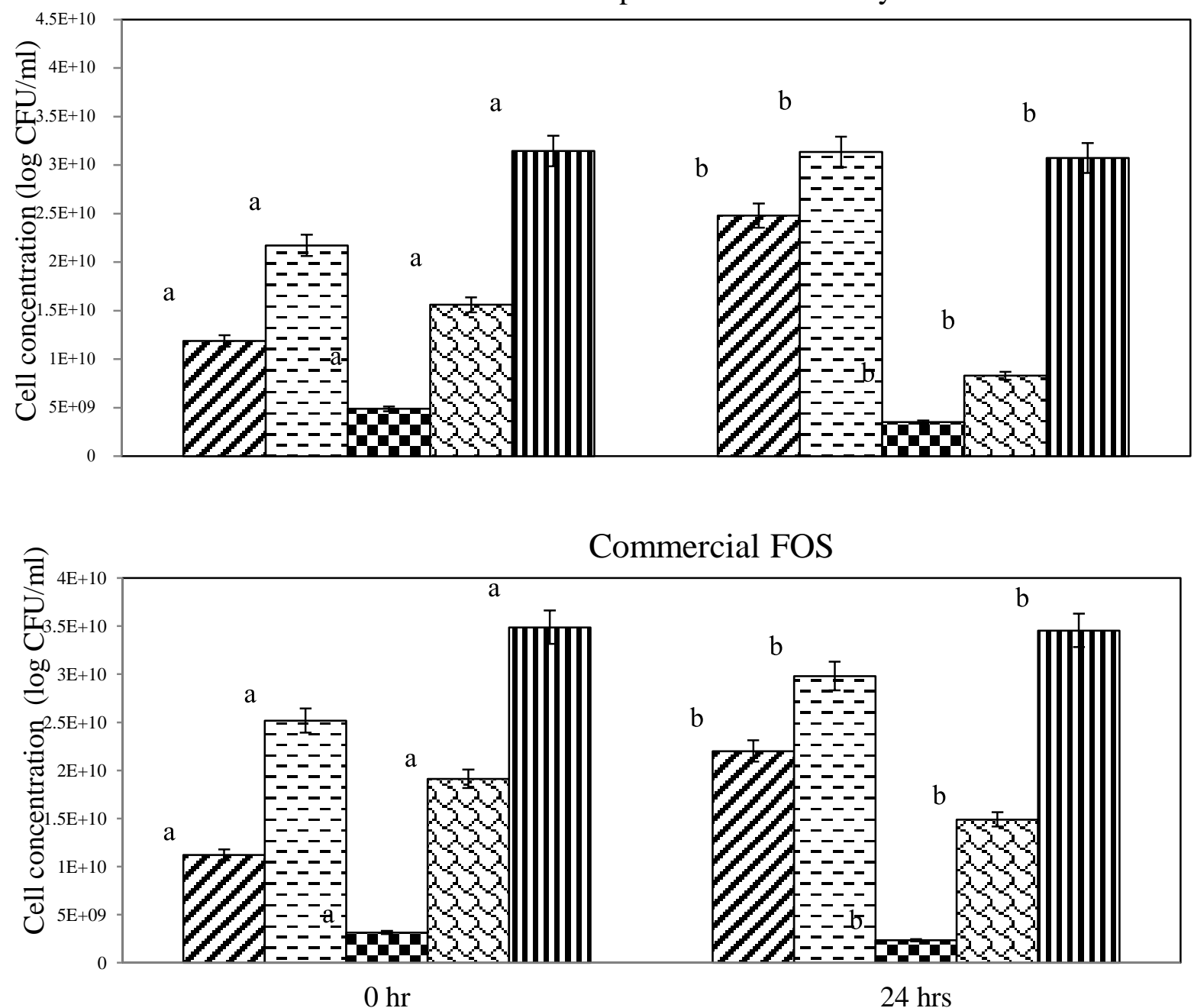

Figure 4. Cell concentration in batch culture using mixed sugar, produced FOS and commercial FOS as carbon sourceat0 and24 hours; ( $\square$ ) Lactobacillus, (国) Bifidobacteria, (田) Bacteroides, ( $\square$ ) Clostridia and (而) Eubacteri. Different letters is statistically significant $(\mathrm{p}<0.05)$ 
Four formulas of canned tuna in spring water and tuna in mayonnaise and pouched tuna in salad cream and tuna in thousand island cream with added inulin were developed for commercial production. An addition of $5 \%$ inulin for tuna in spring water and $7 \%$ inulin for tuna in mayonnaise, tuna in thousand island and tuna in salad cream are recommended. In clinical study of tuna in spring water and tuna in salad cream added 5\% inulin, it was found that inulin addition helps on improve of bowel regularity. The changes in selected bacterial populations in threestage continuous culture that presented prebiotic index are shown in Figures 5.

Vessel 1

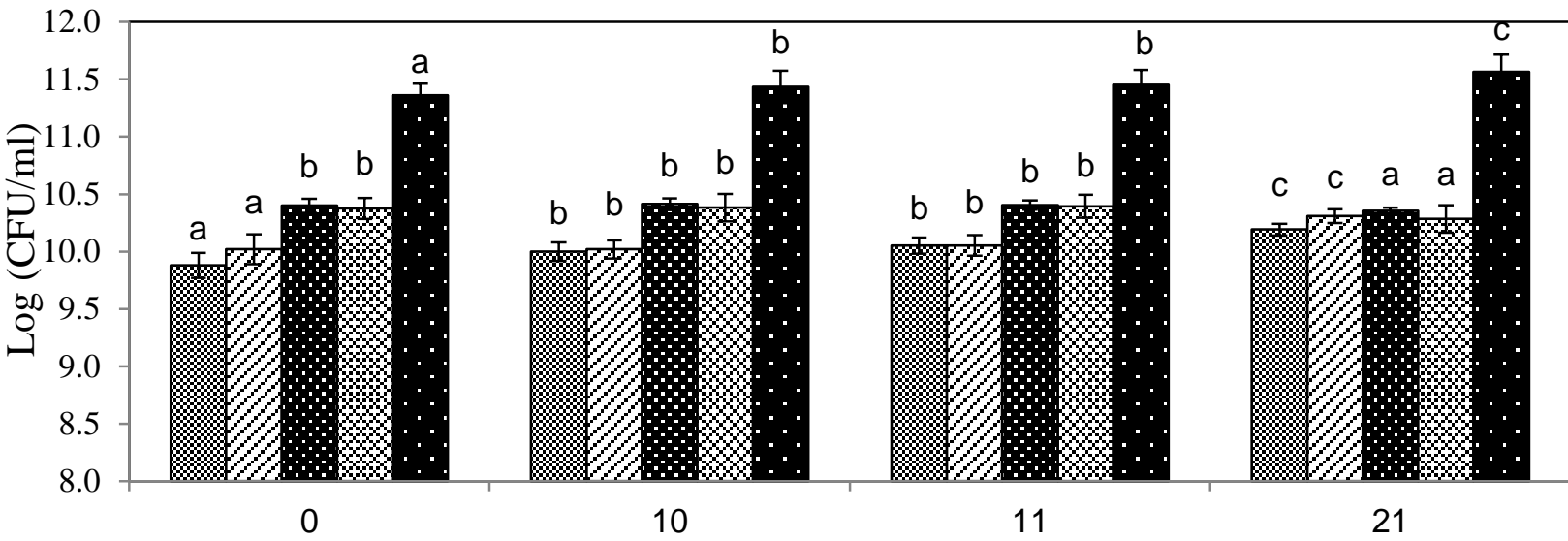

Vessel 2

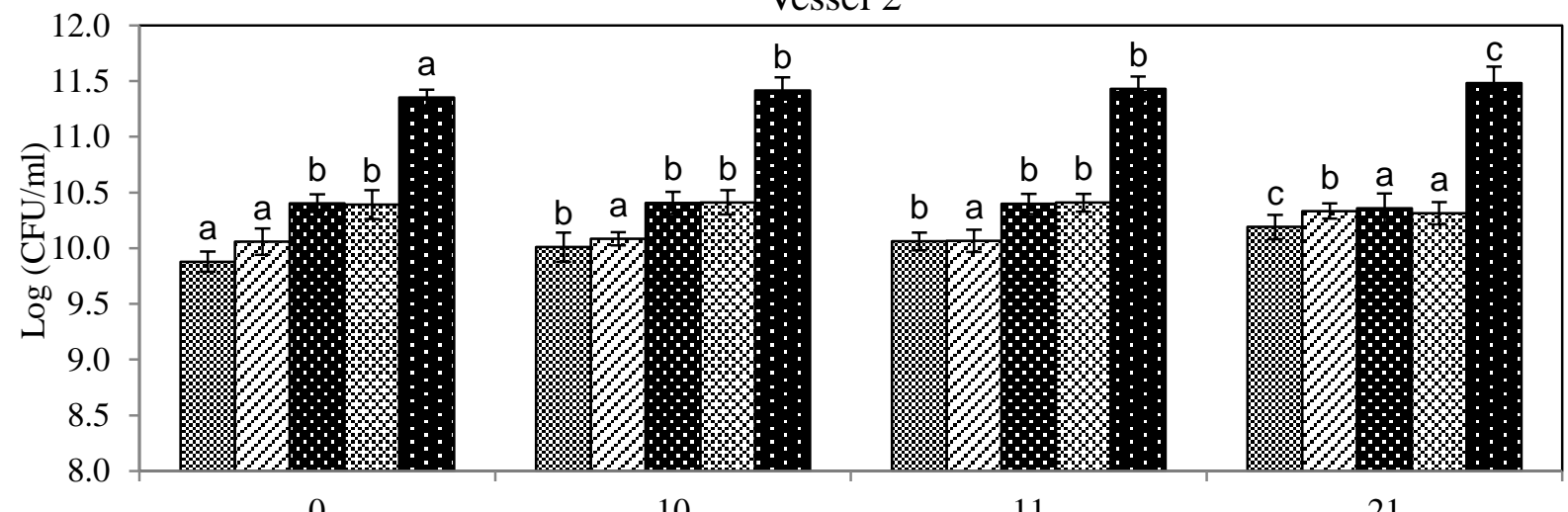

Vessel 3

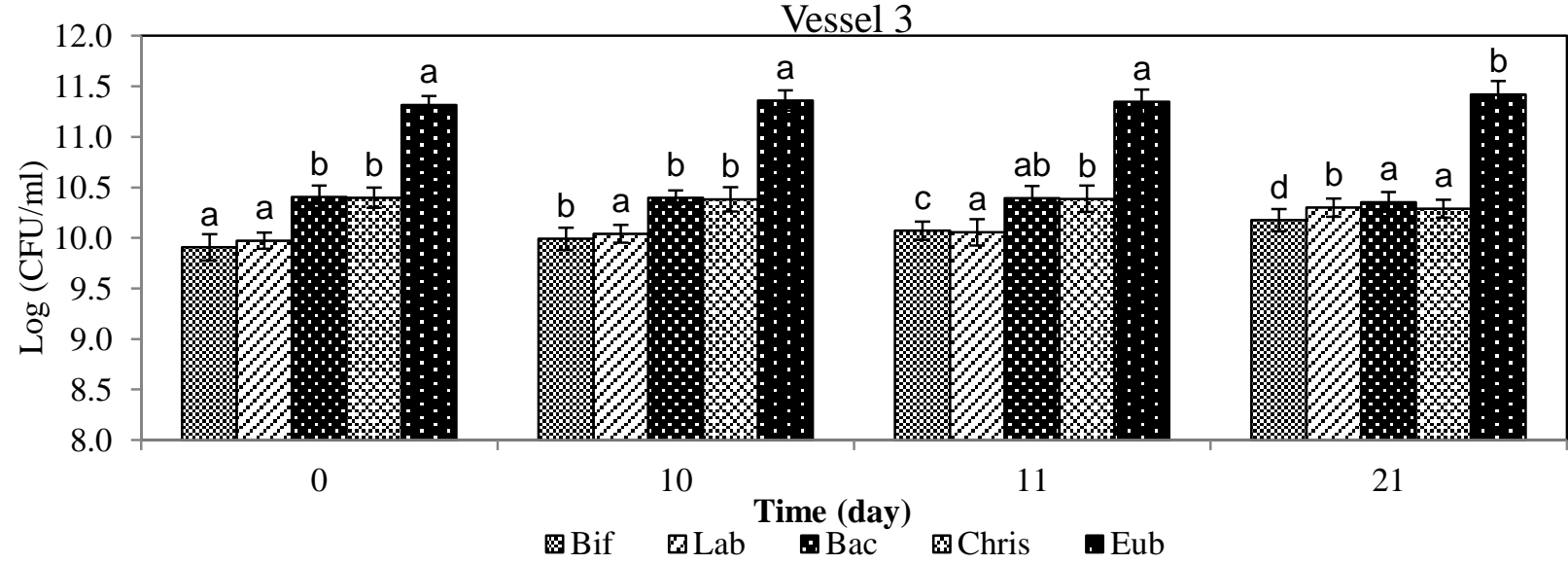

Figure 5. Numbers of fecal bacteria in three-stage continuous fermentation of tuna in spring water added 5\% inulin. Values with different superscripts within the same bacterial species mean it has significantly difference $(\mathrm{p}<0.05)$. 
The results showed that the highest prebiotic effect was found in tuna in spring water added $5 \%$ inulin. The prebiotic index (PI) of tuna in spring water added 5\% inulin in vessel 1, 2 and 3 was 1.28, 1.63 and 1.82, respectively. The prebiotic index of tuna in salad cream added 5\% inulin in vessels 1,2 and 3 was $0.93,0.73$ and 0.77 , respectively. The result gives a positive prebiotic index of both tuna products added 5\% inulin. Thus addition of 5\% inulin to standard formulae of tuna product resulted in significantly $(p<0.05)$ inc rease of beneficial colonic bacteria.

By-product from rubber wood sawdust could be used as alternative source of xylooligosaccharide (XOS). The extract obtained by acetic acid extraction at various conditions. It was found that acetic extraction produced mostly XOS whereas alkaline extraction produced mostly xylan. XOS derived by acid extraction found only at high temperatures $\left(150\right.$ and $\left.200{ }^{\circ} \mathrm{C}\right)$ and longtime at least 1 hour. Optimal condition for extraction of the sawdust by acid under high temperature was $150-200{ }^{\circ} \mathrm{C}$ for 1-2 hours giving XOS with MWCO in the range of 8-11 KDa (Table 3).

Table 3. Molecular weight distribution of xylan and XOS rubber wood sawdust extracted by acetic acid

\begin{tabular}{lllll}
\hline Treatment & Conc. of acid $(\%)$ & Temp. $\left({ }^{\mathbf{0}} \mathbf{C}\right)$ & Time $(\mathbf{m i n})$ & MW (Daltons) \\
\hline 1 & 0 & 100 & 60 & - \\
2 & 0 & 150 & 0 & - \\
3 & 0 & 150 & 120 & 8,034 \\
\hline 4 & 2.5 & 200 & 60 & - \\
5 & 2.5 & 100 & 0 & - \\
6 & 2.5 & 100 & 120 & - \\
7 & 2.5 & 150 & 60 & - \\
8 & 2.5 & 200 & 0 & - \\
9 & 2.5 & 200 & 120 & 138.120 \\
\hline 10 & 5 & 100 & 60 & - \\
11 & 5 & 150 & 0 & - \\
12 & 5 & 150 & 120 & 11,465 \\
13 & 5 & 200 & 60 & 9,045 \\
\hline
\end{tabular}

Among eight edible 8 commercial mushrooms, Schizophyllum commune had highest total $\beta$ glucan content (59.87\% dry basis) and the lowest costof mushroom (0.06 USD/g $\beta$-glucan). The secondorder was Auricularia auricula Judae had $\beta$-glucan of $31.51 \%$ (of total glucan) and the cost of mushroom was $0.07 \mathrm{USD} / \mathrm{g} \beta$-glucan as shown in Table 4. 
Table 4. Summary of cost of mushroom, yield and $\beta$-glucan content and cost/ $\beta$-glucancontent of eight mushrooms

\begin{tabular}{|c|c|c|c|c|c|}
\hline Name & 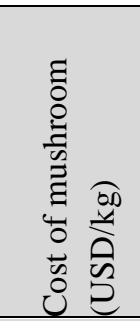 & 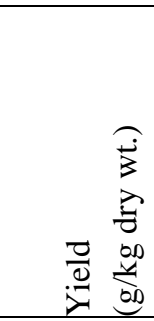 & 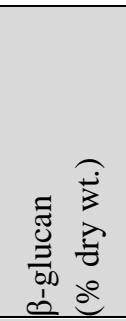 & 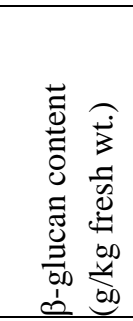 & 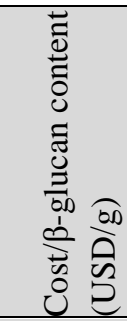 \\
\hline Schizophylum commune $\mathrm{Fr}$ & 6.06 & 134.69 & 59.87 & 80.65 & 0.06 \\
\hline Auricularia auricula Judae & 1.82 & 79.99 & 31.51 & 25.20 & 0.07 \\
\hline Pleurotus sajor-caju $(\mathrm{Fr})$ Sing & 3.03 & 101.13 & 37.61 & 38.04 & 0.08 \\
\hline Pleurotus osttreatus (Fr) Kummer & 6.06 & 104.33 & 32.93 & 34.36 & 0.18 \\
\hline Volvariella vovacea (Bull, Ex, Fr) Sing & 4.85 & 107.40 & 27.85 & 29.91 & 0.16 \\
\hline Lentinus edodes (Berk) Sing & 10.61 & 145.58 & 25.50 & 37.12 & 0.29 \\
\hline Flammulina velutipes (Curt, Ex, Fr) Sing & 4.55 & 84.35 & 19.37 & 16.34 & 0.28 \\
\hline Boletus griseipurpureus Corner & 6.06 & 60.50 & 12.09 & 7.31 & 0.83 \\
\hline
\end{tabular}

\section{DISCUSSION}

Prebiotic differs from the classical dietary fibers specifically soluble dietary fibers which selectively stimulates the growth and/or activity of beneficial bacteria, i.e. bifidobacteria and lactobacilli species [12]. Recent research works on prebiotics in Thailand including screening of prebiotics from natural occurring in fruits and vegetables. However, cheaper samples such as wastes from juice industry, vegetable processing factory and agricultural by-products are more interested because it has low cost for production. Raw materials used for industrial production of inulin are chicory and artichoke. Roots of these plants contained about $60 \%$ and $25 \%$ (dry wt.) inulin, respectively [13]. However, the maximum content of oligosaccharides found in our researches was less than $10 \%$ i.e. dragon fruit contained 5-8\% FOS [14]. Alternative way to obtain high content of oligosaccharides might be succeeded by enzymatic synthesis approach such as GOS and FOS production from novel enzyme with high productivity and more specificity. A novel source of $\beta$-galactosidase in our study can be applied for production of low lactose milk with high GOS by a single step and this process has been patented. Plant tissue culture is also a new approach for production of FOS. XOS is one of emerging prebiotic due to it has high prebiotic effect even at low dose and commercial XOS is made from corncobs [15]. Any raw material suitable for production of XOS have to contain high content of xylans. Currently, commercial $\beta$-glucans have been produced either from oat and barley or brewery's yeast [16]. However, our recent data in rat study on immune stimulation showed that $\beta$-glucans from mushroom has high effective comparable to yeast $\beta$-glucans. Today consumers are concerning for nutraceuticals and functional foods containing active ingredients [17]. Prebiotics are more widely used in foods particular in dairy products. Furthermore, health claim of product containing prebiotic need to be clinically proven.

\section{CONCLUSIONS}

Prebiotic differs from the classical dietary fibers specifically soluble dietary fibers which selectively stimulates the growth and/or activity of beneficial bacteria, i.e. bifidobacteria and 
lactobacilli species. Recent research works on prebiotics in Thailand including oligosaccharides from natural occurring in fruits and vegetables, oligosaccharides from enzymatic synthesis such as galactooligosaccharide (GOS) and short chain fructooligosaccharide (scFOS). Xylooligosaccharide (XOS) from rubber wood sawdust and $\beta$-glucan from edible mushrooms. Application of inulin in tuna products have been clinically proven on gut health function.

List of Abbreviations: LAB, lactic acid bacteria; GOS, galactooligosaccharide; scFOS, shortchain fructooligosaccharide; XOS, xylooligosaccharide; IMO, isomaltooligosaccharide; SOS, soybean oligosaccharide; SCFA, short-chain fatty acid; PI, prebiotic index; FTase, fructosyltransferase; FISH, fluorescence in situ hybridization; DP, degree of polymerization; MWCO, molecular weight cut-off; HPSEC, high performance size exclusion chromatography

Competing Interests: The authors declare that they have no conflicts of interest.

Author's Contributions: All authors contributed to these studies.

Acknowledgments and Funding: These works are supported by the research grants from Thailand Research Fund (TRF) and the Higher Education Research Promotion and National Research University Project of Thailand, Office of the Higher Education Commission, Ministry of Education, Thailand.

\section{REFERENCES}

1. Rastall RA. Emerging prebiotics. In LFRA Ingredients Handbook: Prebiotics and Probiotics. Edited by Gibson GR, Angus FJ. Surrey: Leatherhead Food; 2000:69-83.

2. Tuohy KM, Rouzaud GCM, Brück WM, Gibson GR. Modulation of the human gut microflora towards improved health using prebiotics-assessment of efficacy. Curr Pharm Design 2005, 1:75-90.

3. Gonzalez, NJ, Adhikari K, Sancho-Madriz MF. Sensory characteristics of peachflavored yogurt drinks containing prebiotics and synbiotics. Food Sci Technol 2010, 28:412-420.

4. Vernazza CL, Rabiu BA, Gibson GR. Human colonic microbiology and the role of dietary intervention: introduction to prebiotics. In LFRA Ingredients Handbook: Prebiotics and Probiotics. Edited by Gibson GR, Angus FJ. Surry: Leatherhead Food; 2006:1-28.

5. Marteau PR, de Vrese M, Cellier CJ, Schrezenmeir J. Protection from gastrointestinal diseases with the use of probiotics. Am J Clin Nutr 2001, 73:430-436.

6. Wichienchot S, Thammarutwasik P, Jongjareonrak A, Chansuwan AW, Hmadhlu P, Hongpattarakere H, Itharat A, Ooraikul B. Extraction and analysis of prebiotics from selected plants from southern Thailand. Songklanakarin J Sci Technol 2011, 33:517523.

7. Hemmaratchirakul J, Jaturapiree P, Prueksasri S, Wichienchot S. Production of galactooligosaccharide by $\beta$-galactosidase from Lactobacillus pentosus var. plantarum BFP32. Inter Food Res J, in press. 
8. Prakobpran P, Wichienchot S, Ngampunya B, Jaturapiree P. Fructo-oligosaccharide production by fructosyltranferese from Jerusalem artichoke. MSc thesis. Price of Songkla University, Interdisciplinary Graduate School of Nutraceutical and Functional Food; 2014.

9. Rueangwatcharin U, Wichienchot S. Digestibility and fermentation of tuna products added inulin by colonic microflora. Inter Food Res J 2015, 22(5):2068-2077.

10. Lamtumluk D, Wichienchot S, Youravong W. Xylooligosaccharide production from rubber wood sawdust. MSc thesis. Price of Songkla University, Interdisciplinary Graduate School of Nutraceutical and Functional Food; 2014.

11. Ampai A, Wichienchot S. Production of $\beta$-glucans from edible mushrooms. MSc thesis. Price of Songkla University, Interdisciplinary Graduate School of Nutraceutical and Functional Food; 2015.

12. Wichienchot S. and Chinachoti P. Prebiotic oligosaccharides: origins and production, health benefits and commercial applications. In Oligosaccharides: Sources, Properties and Applications. Edited by Gordon NS. New York: Nova Science Publishers Inc; 2011:59-83.

13. Loo JV, Coussement P, Leenheer LD, Hoebregs H, Smits G. On the presence of inulin and oligofructose as natural ingredients in the western diet. Crit Rev Food Sci Nutri 1995, 35(6):525-552.

14. Wichienchot S, Jatupornpipat M, Rastall RA. Oligosaccharides of pitaya (dragon fruit) flesh and their prebiotic properties. Food Chem 2010, 120:850-857.

15. J.L Alonso, H Domínguez, J.C Parajó1, M.J Vázquez, J.L Alonso, H Domínguez, J.C Parajó1, Vázquez MJ, Alonso JL, Domínguez H, Parajó JC. Xylooligosaccharides: manufacture and applications. Trends in Food Sci Technol 2000, 11(11):387-393.

16. Ahmad A, Anjum FM, Zahoor T, Nawaz H, Dilshad SMR. Beta glucan:a valuable functional ingredient in foods. Crit Rev Food Sci Nutri 2012, 52(3):201-212.

17. Ho CT. Editorial overview: functional foods and nutrition. Current Opin Food Sci 2015, 2:vi-vii. 